\title{
ONTOLOGY AND SEMANTICS: AN ANTI-REALISTIC READING OF THE TRACTATUS
}

\begin{abstract}
According to the received view, the Tractatus would present a realistic conception of the meaning of a declarative sentence: that meaning would be explained in terms of evidence-transcending, not epistemically-constrained, truth-conditions. In this paper, I make a case against such a contention. If states of affairs are identified with possible combinations of phenomenal objects, the truth-conditions of an elementary proposition inevitably collapse onto its assertability-conditions: the existence of the state of affairs depicted by the proposition would be both the condition for its being true and, at the same time, the condition for our recognition of its being true. Moreover, the finiteness of logical space (the set of all phenomenal states of affairs) would ensure the decidability, in principle, of all meaningful propositions, and hence would preserve the general validity of the laws of classical logic. Lastly, the problem of the relationship between the overt verificationism of Wittgenstein's 1929-1933 writings and the Tractatus's ontological and semantic views, is dealt with.
\end{abstract}

\section{Introduction}

Two radically opposite answers have been given to the question: how should the position of the Tractatus be assessed with respect to the controversy between realism and anti-realism in semantics, framed in the terms set out as standard by Dummett's investigations on the topic? Dummett himself was resolute in putting the Tractatus on the side of semantic realism: 'A verificationist theory of meaning differs radically from the account of meaning as given in terms of truth-conditions implicit in Frege's work and explicit in Wittgenstein's Tractatus. On a theory of the latter kind, the crucial notions for the theory of meaning are those of truth and falsity: we know the meaning of a sentence when we know what has to be the case for that sentence to be true. ${ }^{1}$ Some years later, Dummett made the same point as follows: '[Knowledge of the content of an assertion], as the tradition of Frege, the Tractatus and Davidson would have it, is a grasp of what would

1 Dummett (1978, p. 379). 
make such an assertion true, independently of whether we have any means of determining that it does or does not obtain.'

Dummett's interpretation has been received wisdom from the $70 \mathrm{~s}$ onwards. Influential philosophers like Kripke have substantially shared it. What Kripke calls 'the simplest, most basic idea of the Tractatus' is presented by him as follows: 'a declarative sentence gets its meaning by virtue of its truth-conditions, by virtue of its correspondence to facts that must obtain if it is true, independently of any consideration of the conditions which entitle the speaker to assert it, and of the role the practice of assertion plays in our form of life. ${ }^{3}$ In the Cambridge Dictionary of Philosophy, the same assessment of the position of the Tractatus in the development of semantics is made by Lepore: 'Verificationism ... differs radically from the account that identifies meaning with truth-conditions, as is implicit in Frege's work and explicit in Wittgenstein's Tractatus. ${ }^{4}$

At the other, opposite side of the story, early logical positivists were the first to read off from the Tractatus a verificationist, and hence a strongly antirealistic, conception of sentential meaning: the understanding of a sentence would consist in the knowledge of an empirical method to determine, at least in principle, whether the sentence is true or false (an empirical method of decision). There is plenty of textual evidence for the attribution of that interpretation of the Tractatus to logical positivists. ${ }^{5}$ It is crystal clear and, at the same time, remarkable, that logical positivists plainly construed what is usually considered the manifesto of the truth-conditional model of sentential meaning, i.e. section 4.024 of the Tractatus ('To understand a proposition means to know what is the case if it is true') in a verificationist spirit. For logical positivists, verificationism was nothing but a mere gloss on the above formulation of the truth-conditional conception of meaning. More recently, other authoritative Wittgenstein scholars, like Hacker and Glock, have maintained that the Tractatus was actually committed to empirical verifiability as the criterion for sentential meaning, although both make a distinction between the acceptance of such a criterion and the endorsement of the principle of verification, as it was understood by the members of the Vienna Circle and, though with some caution, by Wittgenstein himself in the years $1929-33 .^{6}$

Given that background, there are three themes I want to deal with in this paper. First, if the distinction between realism and anti-realism is traced in

\footnotetext{
2 Dummett (1991, p. 102).

3 Kripke (1982, p. 72).

4 Lepore (1995, p. 834).

5 See, among many others, Carnap (1936-1937, I, $₫ 2$ ) and Waismann (1967, Anhang B, $\$ 6)$.

6 See Hacker (1986, pp. 138-40), (1996, p. 53) and Glock (1996, p. 382).
} 
the terms familiar since Dummett's work, the main problem which we have to tackle is: are the Tractatus truth-conditions of a proposition to be conceived of as transcending the speaker's capacity to recognize whether they obtain or not? In other words: are the Tractatus truth-conditions of a proposition evidence-transcending? Second, if-as I am going to suggest-the Tractatus truth-conditions of a proposition are to be understood in an anti-realistic way, is the further claim justified that knowing the truth-conditions of a proposition amounts to knowing a method of decision (in principle) of its truth-value? Third, is the appeal to the verification principle (to understand a proposition is tantamount to knowing how the issue of its truth or falsity is to be decided), which characterizes Wittgenstein's writings of the early Thirties, just an explicit formulation of the Tractatus conception, albeit a formulation that cannot be found in those very terms in the Tractatus, or is there something new in the views he put forward in those years? Sections 2 of the paper is devoted to give an answer to the first two questions, section 3 to the last question.

\section{Semantic Anti-Realism and Phenomenalistic Ontology}

Let us suppose that the facts into which the world divides (TLP 1.2) are obtaining combinations of phenomenal objects (for instance, obtaining combinations of a phenomenal colour, a visual place and a moment of phenomenal time, i.e. existing colour-spot-moments). This implies that states of affairs should be conceived of as possible combinations of those phenomenal objects or, equivalently, as phenomenal complexes whose components are those phenomenal objects. In my interpretation, the Tractatus ontology would be, according to Nelson Goodman's classification and terminology, a realistic system, where 'realistic' is opposed to 'particularistic': objects would be phenomenal qualities, or qualia, and hence, from a metaphysical point of view, they would belong to the category of abstract universals. In a particularistic system, on the contrary, concrete spatially and temporally bounded particulars, be they either sense-data or phenomenal events, are taken as basic units ${ }^{7}$. An obtaining state of affairs would be a concrete instantiation of each one of the phenomenal universals, or qualia, which are its components. Accordingly, an elementary proposition should be conceived of as a combination of the names of the phenomenal components of a corresponding state of affairs: each name stands for, is proxy for, is representative of (in the original German text: steht für, vertritt) one constituent of the state of affairs, one object, and the elementary proposition as a whole represents (in the original German text: darstellt, vorstellt) or

7 It is worth noting that the ontological opposition realistic system/particularistic system in Goodman's sense has nothing to do with the controversy realism/anti-realism in semantics. See Goodman (1951, pp. 142-5). 
depicts (in the original German text: abbildet) their possible combination, that is, the state of affairs.

Of course, here I will not go into the exegetical and theoretical justification of my reading of the Tractatus ontology (logical atomism). ${ }^{8}$ What matters for us are the consequences of our ontological hypothesis, as far as the realism/anti-realism controversy is concerned. As section 4.024 of TLP says, one understands an elementary proposition if one knows what is the case if the proposition is true. As an elementary proposition is true if, and only if, the state of affairs it depicts obtains, is a fact, one understands an elementary proposition if, and only if, one knows what state of affairs it depicts (the state of affairs it depicts is what is the case if the proposition is true). This knowledge amounts to the knowledge of the truth-conditions of the proposition, because it is exactly the obtaining of that state of affairs that is the condition for its truth: if that state of affairs obtains, the proposition is true, and if the proposition is true, that state of affairs obtains.

Now, if a state of affairs is of a phenomenal nature, as we are supposing it is, speaking of truth-conditions of an elementary proposition, whose fulfilment or unfulfilment we could be unable in principle to recognize, would have no sense at all. Within the phenomenalistic framework, the existence of the state of affairs depicted by an elementary proposition is, at the same time, the condition for its being true and the condition for us to recognize that it is true. For instance, if the presence of a colour-spot-moment in my visual field is the condition for the truth of the elementary proposition that represents it and asserts that it obtains, then I am always able in principle to establish whether that truth-condition is fulfilled or not: visual experience enables me to settle the question. The truth-conditions of an elementary proposition do not transcend the evidence because their being fulfilled, or not, can always be recognized by the speaker. Even though the use of Dummett's jargon with reference to the Tractatus could sound anachronistic, we could safely say that our ontological hypothesis makes the truth-conditions of an elementary proposition coincide with its assertability-conditions: the fulfilment of the former is eo ipso the fulfilment of the latter. As a consequence, no difference can be traced between knowing that so-and-so is the case if $p$ is true (knowing the truth-conditions of $p$ ) and knowing how to determine whether so-and-so is the case (knowing the conditions for ascribing truth to $p$ or, equivalently, for asserting $p$ ): there is no conceptual room for a notion of truth-conditions of an elementary proposition whose fulfilment we could be unable in principle to ascertain ${ }^{9}$. For that reason, the adoption of the Principle of Bivalence for elementary propositions (what Wittgenstein calls 'bipolarity') does not entail

8 For an overall and articulate presentation of this interpretation of the ontology of the Tractatus, and of the exegetical and theoretical reasons backing it, see Frascolla (2004, 2007, 2010).

9 Contrary to Marconi's opinion in his (2002b, p. 4). 
any endorsement of the classical, not evidence-constrained, conception of truth: an elementary proposition is decidable in principle and thus is not determinately true or false independently of our capacity to establish which one of the two cases holds. Every elementary proposition is either true or false, but only in the narrow, epistemically constrained, sense that it is, in principle, either recognizably true or recognizably false.

The extension of the anti-realistic conception of the truth-conditions from the case of elementary propositions to all meaningful propositions is straightforward, given the Tractatus identification of the latter with the truthfunctions of the former (TLP 5). It is expedient, however, to deal separately with the case of a truth-function that is constructed out of $n$ elementary propositions by means of sentential connectives, and the case of universally and existentially quantified propositions. Only in this way, the problem of the finiteness of the domain of objects and of the domain of states of affairs will emerge in connection with the adoption of the anti-realistic conception of the truth-conditions of propositions.

Let us consider, first, a proposition $\alpha$ that is an arbitrary truth-function of $n$ elementary propositions $p_{1}, p_{2}, \ldots, p_{n}$, and let us sum up the procedure by which it is constructed out of $p_{1}, p_{2}, \ldots, p_{n}$. Following Wittgenstein, a truth-possibility of $n$ elementary propositions $p_{1}, p_{2}, \ldots, p_{n}$ is an assignment either of Truth (T) or of Falsity (F) to each one of them. A truth-possibility of $n$ elementary propositions $p_{1}, p_{2}, \ldots, p_{n}$ corresponds to a combination of the obtaining and non-obtaining of the states of affairs depicted by the elementary propositions $p_{1}, p_{2}, \ldots, p_{n}$. For every $i$ such that $1 \leq i \leq n$, let $\mathrm{S}_{i}$ be the state of affairs depicted by the elementary proposition $p_{i}$; if, in a given truth-possibility of $p_{1}, p_{2}, \ldots, p_{n}$, the elementary proposition $p_{i}$ has been assigned Truth, then we take the state of affairs $\mathrm{S}_{i}$ as obtaining; if $p_{i}$ has been assigned Falsity, then we take the state of affairs $S_{i}$ as non-obtaining. Given $n$ elementary propositions $p_{1}, p_{2}, \ldots, p_{n}$, a proposition $a$ can be constructed by expressing either agreement or disagreement with each one of the truthpossibilities of $p_{1}, p_{2}, \ldots, p_{n}$, and hence with each one of the combinations of the obtaining and non-obtaining of the states of affairs $S_{1}, S_{2} \ldots S_{n}$. The related sign procedure consists in coordinating $\mathrm{T}$ (Truth) to each truth-possibility with which agreement is expressed, and F (Falsity) to each truth-possibility with which disagreement is expressed (in the Tractatus original notation, no sign is coordinated to the latter truth-possibilities).

This is the way Wittgenstein presents the semantics of the so-called (not by him) molecular propositions, that is, propositions generated by means of the usual sentential connectives from a set of $n$ elementary propositions $p_{1}$, $p_{2}, \ldots, p_{n}$. The truth-conditions of such a proposition $\alpha$ are fulfilled if, and only if, one of those combinations of the obtaining and non-obtaining of the states of affairs $\mathrm{S}_{1}, \mathrm{~S}_{2} \ldots \mathrm{S}_{n}$ for which $\alpha$ is true, is realized in the world. Since for every $i$ such that $1 \leq i \leq n$, one can always ascertain, at least in principle, 
whether Si obtains or not, one can recognize whether the truth-conditions of $\alpha$ are fulfilled or not by simply checking that circumstance for every Si: thus, the truth-conditions of $a$ are not evidence-transcending. By putting things in a more usual way: if each one of the elementary propositions $p_{1}, p_{2}, \ldots, p_{n}$ is decidable in principle, as it happens according to our interpretation, then the truth-value of a can mechanically be computed by means of its truthtable, once the truth-values of $p_{1}, p_{2}, \ldots, p_{n}$ have been established: thus $\alpha$ is decidable in principle as well.

Without going into the details of Wittgenstein's treatment of generality, let us examine now the two simplest cases of quantified propositions. Suppose that the values of the propositional variable $f x$ are elementary propositions; the proposition $(x) . f x$ is true only for that truth-possibility of the values of $f x$ in which they all are true, i.e. only for that combination of the obtaining and non-obtaining of the states of affairs depicted by those values in which they all obtain, whereas the proposition $(\exists x) . f x$ is false only for that truth-possibility of the values of $f x$ in which they all are false, i.e. only for that combination of the obtaining and non-obtaining of the states of affairs depicted by those values in which no one of them obtains. In both cases, the fact that all the elementary propositions that are the values of $f x$ are decidable in principle is not enough to warrant the decidability in principle either of $(x)$. $f x$ or of $(\exists x)$. $f x$. If there are infinitely many elementary propositions that are the values of $f x$, then: a) no finite number of positive outcomes of the checking for the obtaining of the states of affairs depicted by them can rule out the possibility that a negative outcome can occur later; b) no finite number of negative outcomes of the checking for the obtaining of those same states of affairs can rule out the possibility that a positive outcome can occur later. In both cases, one cannot rule out the possibility that we are not able in principle to settle the question whether the truth-conditions of the two propositions at issue are fulfilled or not.

The principle that there are no truth-conditions of propositions, whose fulfilment we could be unable in principle to recognize, can be saved only on condition of limiting to the finite the number of objects and of states of affairs. As known, both the problem of the number of objects and, as a corollary, that of the number of states of affairs, are sanctioned as pseudoproblems by the Tractatus criteria of meaningfulness (TLP 4.1272). Moreover, in TLP 4.463, the infinite logical space is spoken of, and in TLP 4.2211 the hypothesis that there are infinitely many objects and infinitely many states of affairs seems to be presented as conceivable. It seems to me that it is only by resorting to the distinction between the skeletal, schematic ontology, set out before the phenomenal nature of objects and states of affairs is recognized, on the one hand, and the full-blown ontology deriving from that recognition, on the other, that the matter can be settled. ${ }^{10}$ If objects are identified with

10 For the distinction between the skeletal and the full-blown ontology in the Tractatus, see Frascolla (2007, Chapter 3, pp. 60-84). What Wittgenstein is reported to have said in 
qualitative aspects of the phenomenal given, and states of affairs with those finite combinations of objects which are allowed by the internal properties (by the form) of the latter, then the limitation to the finite comes up as quite natural, even though it is only the application of logic that can respond to the question of which phenomenal qualities play the role of objects. The number of discernible qualitative aspects of phenomena in each sense realm is surely finite, and thus the number of all those finite combinations of objects that constitute phenomenal states of affairs or complexes is finite as well. I cannot go into this theme here, but some relevant specifications can sketchily be made in order to back my statement: for instance, that no phenomenal object can occur more than once as a component of one and the same state of affairs, that neither two nor more phenomenal objects of the same form (phenomenal colours, for example) can occur in one and the same state of affairs, that phenomenal times are finite in number, because at death the world does not alter, but comes to an end' (TLP 6.431).

Lastly, it is worth noting that, according to my interpretation, the antirealism of the Tractatus semantics does not make meaningfulness of a proposition depend on empirical circumstances such as the availability of a method of verification, and thus does not imperil Wittgenstein's well known thesis of the independence of the semantic sphere from contingent matters of any sort. ${ }^{11}$

\section{From the Anti-Realism of the Tractatus to the Strong Verificationism of the Early Thirties}

In the framework outlined above, two questions can easily be answered. First, one can account for section 4.063 of the Tractatus, where Wittgenstein seems to overlook the crucial difference between truth-conditions of a proposition and conditions that justify predicating truth of a proposition, i.e. ascribing truth to it: "In order to be able to say: " $p$ " is true (or false), I must have determined in what circumstances I call " $p$ " true, and in so doing I determine the sense of the proposition'. Here the sense of a proposition is not identified with the conditions for it to be true, but with the conditions for us to ascribe truth to it (to call it 'true'). The latter (truth-ascription conditions) are the conditions that, if fulfilled, entitle the speaker to take the former (truthconditions) as fulfilled, and thus the conditions that justify his assertion of the proposition. Thanks to our interpretive conjecture, what could appear as a failure on Wittgenstein's part in acknowledging the difference between

Wittgenstein (1980, p. 119) about the treatment of infinity as a number in the Tractatus, should call for an explanation as well. Be that as it may, whoever knows even just a little about how Wittgenstein deals with infinity in the Tractatus remains incredulous in front of that report and cannot help entertaining doubts about its accuracy.

11 This is my rejoinder to Marconi's contention in his (2002a). 
truth-conditions of a proposition and conditions for the ascription of truth to a proposition, reveals itself as the inevitable corollary of the collapse of the former onto the latter, brought about by the phenomenalistic nature of the ontology on which the Tractatus semantics is founded.

The second question that can find a simple answer regards logic. How can the acceptance of the principles of classical logic peacefully coexist with the anti-realistic interpretation of truth-conditions I have extracted from the phenomenalistic ontology of the Tractatus? The immediate answer is: they can coexist because meaningful propositions are decidable in principle and hence what holds of classical truth and falsity holds for recognizable, evidence-constrained, truth and falsity as well.

We come, finally, to the crucial question I want to deal with in this section of the paper, a question that cannot be by-passed. It can be put as follows: even if the phenomenalistic interpretation of the Tractatus ontology is adopted, and its consequences on the semantic opposition between realism and antirealism are consistently drawn, nonetheless a significant absence in the Tractatus should be accounted for. As we saw above, the opposition between a model of sentential meaning based on truth-conditions and a model based on assertability-conditions could have no room in the Tractatus: within the phenomenalistic framework, truth is inevitably evidence-constrained, and truth-conditions, whose fulfilment the speaker could be unable in principle to recognize, are ruled out. In Dummett's sense, the semantics of the Tractatus is plainly anti-realistic.

Yet it is hard to maintain that in the Tractatus Wittgenstein endorsed verificationism, if this conception is characterized by the acceptance of the principle of verification, the principle according to which, understanding a proposition consists in knowing an empirical method to establish its truthvalue. As a matter of fact, no trace of the formulation of that principle is to be found in the Tractatus. Moreover, it is an equally undeniable, wellknown fact that, especially in the writings from 1929 to 1933, Wittgenstein himself explicitly stated that principle as the basic principle of the grammar of the assertoric discourse. In those writings, present experience is put at the foundation of those procedures by whose application a conclusive verification or falsification of genuine propositions can be obtained. Accordingly, the understanding of such propositions is identified with the knowledge of those procedures. ${ }^{12}$ Now the question inevitably arises: what is changed in the passage from the Tractatus to the writings of the intermediate phase, that prompted Wittgenstein to give an explicit formulation of a principle never mentioned in the Tractatus? And, symmetrically, how can one explain that

12 Several references to passages from Wittgenstein's texts of the so-called intermediate phase, where the verification principle is explicitly stated, can be found in Hacker, Glock and Marconi cited above. 
absence in the Tractatus, if the phenomenalistic orientation was already present there?

In order to give an answer to these questions, it is expedient to look at the semantic conception of the Tractatus from a slightly different point of view. The pivotal thesis that all meaningful propositions, quantified propositions included, are truth-functions of elementary propositions depicting phenomenal states of affairs amounts to the general thesis of the complete translatability of all meaningful propositions into the bottom-level phenomenalistic language. In this respect, the Tractatus is written in the wake of the logical construction of the world proposed by Bertrand Russell in Our Knowledge of the External World and in The Relation of Sense Data to Physics, and is a forerunner of the logical construction proposed by Rudolf Carnap in Der logische Aufbau der Welt. ${ }^{13}$ In my opinion, the peculiarity of the Tractatus lies in the fact that the basic units of the system are phenomenal universals, not phenomenal particulars (neither sense-data, as in Russell, nor Erlebnisse, as in Carnap). If things stand that way, one can easily account for the absence of any formulation of the verification principle in the Tractatus: once a proposition is translated into the phenomenalistic language, its content is completely displayed, and that content, according to the picture theory, directly shows what phenomenal states of affairs, if obtaining, make the proposition recognizably true.

As is well known, insurmountable obstacles undermined a comprehensive and detailed articulation of the Tractatus conception of sentential meaning. I cannot expand on this theme here, and I will limit myself to point out what is relevant to my purposes. For many theoretical reasons, what proved to be unrealizable was the very construction of a phenomenalistic language, the translatability into which had been taken over by Wittgenstein as the criterion for sentential meaningfulness in the Tractatus. If the phenomenal objects of the Tractatus logical atomism cannot be identified, phenomenal states of affairs cannot either; accordingly, elementary propositions are doomed to be left in obscurity, and the whole enterprise is left pending in the void. Nonetheless, the admission of the failure does not lead Wittgenstein to giving up the conception that anchors the semantic foundations of assertoric discourse in the possible present experience of the speaker. The old goal can be, and has to be, achieved in a new way: not by means of a by now acknowledged impracticable translation into a mythical 'phenomenological language' or 'primary language', but by means of a grammatical inquiry that clarifies how the truth or falsity of our assertions can conclusively be established on the basis of the present experience.

Thus the Tractatus anti-realistic conception of the truth-conditions of a proposition undergoes a crucial modification that results in the equally

13 See Russell (1914a, 1914b) and Carnap (1928). 
anti-realistic verificationist model. As Marconi has rightly suggested, it is Wittgenstein's conception of 'what it is to know what's the case if $p$ is true' that changes: according to my interpretive conjecture, the translation of $p$ into the phenomenalistic language is no longer required in order to get that knowledge, and mastering a procedure of verification is all that is needed. ${ }^{14}$ The change of the means to reach a goal that is constant through the passage from the Tractatus to the 1929-33 writings is described by Wittgenstein himself as follows: 'A proposition is completely logically analysed if its grammar is made completely clear: no matter what idiom it may be written or expressed in. I do not now have phenomenological language, or "primary language" as I used to call it, in mind as my goal. I no longer hold it to be necessary. All that is possible and necessary is to separate what is essential from what is inessential in our language. That is, if we so to speak describe the class of languages which serve their purpose, then in so doing we have shown what is essential to them and given an immediate representation of immediate experience ... A recognition of what is essential and what inessential in our language if it is to represent, a recognition of which parts of our language are wheels turning idly, amounts to the construction of a phenomenological language. ${ }^{15}$

It goes without saying that many further specifications ought to be made in order to throw light on the intermediate Wittgenstein's verificationism: for instance, the exclusive role of present experience in the procedures of verification, the purported extension of the verificationist approach to mathematics, with the aim of making room for the notion of a not yet proved meaningful mathematical proposition, the criticism to Brouwer's rejection of the Principle of Excluded Middle, and so on. My modest goal in this article has been simply to put in the right perspective both the Tractatus anti-realism and the later transition to that form of verificationism which logical positivists endorsed enthusiastically: however, much of the interpretive work-to detail the issues, so to speak-still remains to be done.

\section{References}

Carnap, R. 1928. Der logische Aufbau der Welt. Leipzig: Felix Miener Verlag. Carnap, R. 1936-1937. 'Testability and Meaning', Philosophy of Science, III, IV.

Dummett, M. 1978. 'The Significance of Quine's Indeterminacy Thesis', in Truth and Other Enigmas. Cambridge Mass.: Harvard University Press.

Dummett, M. 1991. The Logical Basis of Metaphysics. Cambridge Mass.: Harvard University Press.

14 See Marconi (2002b, p. 244). In certain respects, my interpretation is in tune with the reconstruction of the development of Wittgenstein's thought in the early Thirties proposed by Hintikka and Hintikka in their (1986, Chapter 6). 
Frascolla, P. 2004. 'On the Nature of Tractatus Objects', Dialectica, 58, 3.

Frascolla, P. 2007. Understanding Wittgenstein's Tractatus. London-New York: Routledge.

Frascolla, P. 2010. 'An Adequacy Condition for the Interpretation of the Tractatus Ontology', in Wittgenstein: Mind, Meaning and Metaphilosophy. P. Frascolla, D. Marconi, A. Voltolini edss. Basingstoke: Palgrave Macmillan.

Glock, H.J. 1996. A Wittgenstein Dictionary. Oxford: Blackwell.

Goodman, N. 1951. The Structure of Appearance. Cambridge Mass.: Harvard University Press.

Hacker, P.M.S. 1986. Insight and Illusion. Themes in the Philosophy of Wittgenstein. Revised edition. Oxford: Clarendon Press.

Hacker, P.M.S. 1996. Wittgenstein's Place in Twentieth-Century Analytic Philosophy. Oxford: Blackwell.

Hintikka, M., Hintikka, J. 1986. Investigating Wittgenstein. Oxford-New York: Blackwell.

Marconi, D. 2002a. 'Verificationism in the Tractatus?'. Proceedings of the Lagopesole Workshop. Annali della Facoltà di Lettere e Filosofia dell'Università della Basilicata, 11. Potenza.

Marconi D. 2002b. 'Verificationism and the Transition', in Wittgenstein and the Future of Philosophy. A Reassessment after 50 Years/Wittgenstein und die Zukunft der Philosophie. Eine Neubewertung nach 50 Jahren. Wien: öbv et hpt.

Russell, B. 1914a. Our Knowledge of the External World as a Field for Scientific Method in Philosophy. London: Allen and Unwin.

Russell, B. 1914b. 'The Relation of Sense Data to Physics', Scientia, 16, in Mysticism and Logic and Other Essays. 1918. London: Green and Co.

Waismann, F. 1967. Wittgenstein und der Wiener Kreis. Aus der Nachlass herausgegeben von B.F. McGuinness. Oxford: Blackwell.

Wittgenstein, L. 1922. Tractatus logico-philosophicus. English trans. D.F. Pears and B.F. McGuinness, 1961, revised edn. 1974. London: Routledge and Kegan Paul.

Wittgenstein, L. 1964. Philosophische Bemerkungen. R. Rhees ed. Oxford: Blackwell. English trans. R. Hargreaves and R. White, 1975, Philosophical Remarks. Oxford: Blackwell.

Wittgenstein, L. 1980. Wittgenstein's Lectures - Cambridge - 1930-1932. From the Notes of John King and Desmond Lee. D. Lee ed. Oxford: Blackwell. 